\title{
Possible protective effect of curcumin on the thyroid gland changes induced by sodium fluoride in albino rats: light and electron microscopic study
}

\author{
Mohamed Mostafa Abdelaleem ${ }^{1}$, Nashwa Fathy Gamal El-Tahaw ${ }^{2}$, \\ Samah Mohammed Mahmoud AвozaID ${ }^{3}$, Shima Abdel-Baset Abdel-Hakim ${ }^{3}$ \\ ${ }^{1}$ Department of Anatomy, Faculty of Medicine, Minia University, delegated to Deraya University, New Minia, Egypt; \\ ${ }^{2}$ Department of Histology and Cell Biology, Faculty of Medicine, Minia University, Minia, Egypt; ${ }^{3}$ Department of \\ Anatomy, Faculty of Medicine, Minia University, Minia, Egypt \\ E-mail:nashogo@yahoo.com
}

\begin{abstract}
Objectives. Thyroid gland regulates the body's metabolic rate and plays an exquisitely important role in the human health. Fluoride exposure can affect thyroid function. Curcumin is a potent antioxidant that works through several mechanisms. The aim of the present study was to demonstrate the hormonal, histological, and ultrastructural changes occurred in the thyroid gland induced by exposure to sodium fluoride $(\mathrm{NaF})$ and study the possible protective effect of curcumin on the NaF-induced effects.

Methods. Thirty male albino rats were randomly divided into 3 equal groups (10 rats each): the control group, $\mathrm{NaF}$ group, and $\mathrm{NaF}+\mathrm{Curcumin}(\mathrm{NaF}+\mathrm{Cur})$ group. Thyroid-stimulating hormone (TSH), triiodothyronine (T3) and thyroxine (T4) levels were assayed and thyroid tissues processed for light and transmission electron microscopic study.

Results. In NaF group, serum T3 and T4 levels were significantly decreased whereas TSH level was significantly increased compared to the control group. Thyroid tissues showed flattening of the epithelial lining with several follicular cell degenerations, hyperplasia, decreased colloid, disrupted basement membrane, cytoplasmic vacuolations, degenerated mitochondria, widening of rough endoplasmic reticulum cisternae, and vascular congestion compared to the control group. In the $\mathrm{NaF}+\mathrm{Cur}$ group, serum TSH levels were significantly decreased in comparison with $\mathrm{NaF}$ group and no significant difference in comparison with the control group. Thyroid sections appeared apparently normal compared to the control group and $\mathrm{NaF}$ group.
\end{abstract}

Conclusions. Sodium fluoride affected both the function and structure of the thyroid gland while curcumin was protective against these toxic effects.

Key words: thyroid gland, fluoride, curcumin, rats

The thyroid gland regulates the body's metabolic rate and plays an exquisitely important role in human health (Gartner and Hiatt 2007). The thyroid hormones triiodothyronine (T3) and thyroxine (T4) are tyrosine-based hormones produced by the gland that are primarily responsible for regulation of metabolism (de Felice et al. 2004). Iodine is necessary for the production of T3 and T4 (Nabavi et al. 2011). The thyroid hormones act on nearly every cell in the body. They are essential to proper development and differentiation of all the cells in the human body (Jayaprakasha et al. 2006). All metabolically active 
cells require thyroid hormone for proper functioning. Thyroid disruption may have a wide range of effects virtually on every system of the body (Patil and Dhurvey 2015).

Fluoride exposure may influence the thyroid function in some individuals (Carton 2006). Sodium fluoride $(\mathrm{NaF})$ is commonly added to drinking water and decay-preventive ingredients. Foods rich in fluoride include sea food, bony meals, rice, and dark green vegetables such as the tea plant (Petersen and Lennon 2004). Egypt is one of top 21 countries that have problems with endemic fluorosis, where the main pathway of fluoride exposure is the ingestion of tap water from contaminated groundwater sources $(\mathrm{Ng}$ et al. 2003). Exposure to NaF leads to some adverse effects on various organs (Shepherd 2005). The thyroid gland is one of the most sensitive organs in its histopathological and functional responses to excessive amounts of fluoride (Carton 2006). The fluoride affects several parameters of thyroid activity and development (Irizarry et al. 2014).

Several non-enzymatic antioxidants, such as curcumin, possess protective effects against toxicity (Nabavi et al. 2011). Curcumin is the principal curcuminoid of turmeric, which is a member of the ginger family (Zingiberaceae) (Manolova et al. 2014). It works through several mechanisms and as it has been found to slow or stop enzymes that cause inflammation, like cyclooxygenase-2 and 5-lipooxygenase (Surh et al. 2001). Studies have shown that curcumin can modulate over 700 different genes (Kita et al. 2008; Bishayee and Khuda-Bukhsh 2013; Manolova et al. 2014).

The aim of this study was to demonstrate the hormonal, structural, and ultrastructural changes occurred in the thyroid gland induced by exposure to $\mathrm{NaF}$ and study the possible protective effect of curcumin on the NaF-induced effects.

\section{Materials and Methods}

Animals. Thirty males Sprague Dawley albino rats aged 6-8 weeks, weighing 150-200 g and pathogenically free were obtained from the animal house of the anatomy department, Faculty of Medicine, Minia University. Rats were acclimatized for 7 days before starting the experimental procedures. After getting an ethical committee clearance, all the rats were handled in accordance with the standard guide for the care and use of the laboratory animals of Minia Faculty of Medicine.

Reagents. All reagents were obtained from Sigma Company (Sigma Aldrich, Cairo, Egypt). Sodium flu- oride $(\mathrm{NaF})$ was provided in a white powder form and dissolved in drinking water. Curcumin was provided in a powder form and diluted in corn oil.

Experimental design. Animals were randomly and equally divided into 3 groups (10 rats each) as following: the control group - rats received distilled water for 2 weeks; $\mathrm{NaF}$ group - rats received $\mathrm{NaF}$ in drinking water administered through a gastric tube (Patil and Dhurvey 2015) in a dose of $15 \mathrm{mg} / \mathrm{kg}$ b.w./ day for 2 weeks; $\mathrm{NaF}+\mathrm{Curcumin}(\mathrm{NaF}+\mathrm{Cur})$ group rats received curcumin by gastric tube in a dose of $100 \mathrm{mg} / \mathrm{kg} /$ day for one week before receiving $\mathrm{NaF}$ (15 mg/kg/day) and it was continued concomitantly with $\mathrm{NaF}$ for another 2 weeks (El-Marakby and Ismail 2013).

Hormonal assay. By the end of the study, blood samples were collected from all rats and centrifuged. Then the sera were separated and stored at $-20^{\circ} \mathrm{C}$ until analysis. The serum levels of T3 and T4 were determined by chemiluminescence immunoassay using commercial kits (Bunkyo-ku, Tokyo, Japan) (Whithead et al. 1983). The serum thyroid stimulating hormone (TSH) levels were assayed by radioimmunoassay (Tietz 1994).

Hematoxylin and Eosin (H\&E) staining. Specimens were taken from the thyroid and fixed in $10 \%$ formal saline for $24 \mathrm{~h}$, dehydrated in ascending grades of alcohol, cleared with xylene, and embedded into paraffin. Then 5-6 $\mu \mathrm{m}$ sections were cut and stained with H\&E (Bancroft and Gamble 2008).

Semithin sections and ultrastructural study using transmission electron microscopy (TEM). Thyroid specimens removed from 3 groups were fixed with $1 \%$ glutaraldehyde/ $1 \%$ paraformaldehyde in $1 \%$ buffered osmium tetroxide solution. The fixed tissues were post-fixed with osmium tetraoxide and incubated overnight in uranyl acetate. Then, they were embedded into an Araldite-502. Semithin sections of $1 \mu \mathrm{m}$ thickness were cut using a Zeiss microtome and stained with $1 \%$ toluidine blue for light microscopic examination. Subsequently, the specimens were dehydrated through an ascending series of ethanol, treated with propylene oxide, and embedded into an epoxy resin. After heat polymerization, ultrathin sections were cut with a glass knife using an ultramicrotome and double-stained with uranyl acetate and lead citrate (Graham and Orenstein 2007).

Image capture. $\mathrm{H} \& \mathrm{E}$ and semithin section images were digitally captured in bright-field mode using a high-resolution color digital camera mounted on an Olympus microscope (Olympus, Japan), connected to computer and then analyzed using Adobe Photoshop in Histology Department, Faculty of Medicine, Min- 
ia University. Electron microscopic specimens were examined and photographed by a TEM (JEOL, Japan) in Assiut University Electron Microscopic Unit.

Statistical analysis. Statistical analysis was done by SPSS version 19 (SPSS Inc., Chicago, IL, USA). The mean number $(\mathrm{MN})$ and standard deviation (SD) were determined for quantitative parameter in each group. The significance of differences observed in these groups was pooled and assessed by ANOVA test and post HOC test. The probability (p) of less than 0.05 was used as a cut off point for all significant tests.

\section{Results}

Biochemical results (Table 1). Serum T3 and T4 levels showed a significant decrease in $\mathrm{NaF}$ group compared to the control group $(p=0.030,0.001$; respectively). While $\mathrm{NaF}+\mathrm{Cur}$ group showed a significant increase compared NaF group ( $p=0.040,0.01$; respectively) with no significant difference compared to the control group ( $\mathrm{p}=0.325,0.670$; respectively).

Serum TSH levels were significantly increased in $\mathrm{NaF}$ group compared with the control group $(\mathrm{p}=0.005)$ and $\mathrm{NaF}+\mathrm{Cur}$ group $(\mathrm{p}=0.007)$. While no significant difference was observed between $\mathrm{NaF}+\mathrm{Cur}$ group and the control group $(\mathrm{p}=0.670)$.

Histological results. Control group. $\mathrm{H} \& \mathrm{E}$ (Figures 1,2 ) and semithin (Figure 3) sections of the control group showed normal architecture; the gland was formed of variable sized follicles arranged in lobules with the large follicles at the periphery and encapsulated by a connective tissue capsule. Lumina were filled with colloid and surrounded by a single layer of flattened to cuboid cells. The C-cells were noticed either adjacent to follicles (para-follicular) or in groups between follicles (inter-follicular). The lining follicular cells were mostly cuboid in shape and had central rounded vesicular nuclei.

Ultrastructural figures (Figures 4, 5) showed the cuboid follicular cells with large rounded euchro- matic nuclei and numerous apical short microvilli projected into the lumen. They were resting on regular basement membrane. The cytoplasm contained multiple mitochondria of variable sizes, well-developed paralleled cisternae of the rough endoplasmic reticulum, numerous free ribosomes, and pinocytotic vesicles.

NaF group. H\&E (Figures 6, 7) and semithin (Figures 8,9 ) sections of $\mathrm{NaF}$ group showed variable and patchy morphological changes; loss of lobular architecture, variable sized follicles that varied from very large to too small ones. Some of the follicles were ballooned with reduction of colloid or completely empty lumina (Figure 6). Most of epithelial lining of follicles were flattened. Some cells appeared with deep acidophilic cytoplasm and small condensed nuclei; apoptotic figures, and others were exfoliated in the lumen leaving areas of denuded basement membrane (Figure7). Numerous cells of the epithelium lining showed marked vacuolations of cytoplasm (Figure 8). Some adjacent follicles had fused lumina due to follicular membrane disruption and blood capillaries were congested (Figures 7, 9).

Ultrathin sections showed that most of the cells were represented by flat squamous cells with irregular nuclei, thickening of the basal lamina, and infrequent scattered microvilli (Figure 10). Some follicular cells were cuboid and had irregular nuclei with heterochromatin and dilatation of almost cisternae of the rough endoplasmic reticulum. Numerous cytoplasmic vacuoles and infrequent scattered microvilli were also noticed (Figure 11). The cytoplasm of the follicular cell showed multiple swollen mitochondria with disrupted cristae (Figure 12a), dilated cisternae of the rough endoplasmic reticulum, numerous vacuoles in the cytoplasm, and apical lysosomes (Figure 12b). Interestingly, some follicles were lined with stratified more than one layer of cells. The basal cell showed small dense nucleus and dilated rough endoplasmic reticulum, while the upper cell showed numerous

Table 1

Serum triiodothyronine (T3), thyroxine (T4), and thyroid-stimulating hormone (TSH) levels in the studied groups.

\begin{tabular}{lccccc}
\hline Group & Control & \multicolumn{2}{c}{ NaF } & \multicolumn{2}{c}{ NaF+Curcumin } \\
\hline Parameter & Mean \pm SD & Mean \pm SD & p value & Mean \pm SD & p-value \\
T3 (ng/dl) & $84.5 \pm 18.1$ & $57.8 \pm 8.5$ & $0.030^{\mathrm{c}}$ & $73.5 \pm 8.3$ & 0.325 \\
T4 (ng/dl) & $2.5 \pm 0.5$ & $1.4 \pm 0.6$ & $0.001^{\mathrm{c}}$ & $2.1 \pm 0.6$ & $0.040^{\mathrm{d}}$ \\
TSH (ng/dl) & $0.7 \pm 0.3$ & $2.0 \pm 0.4$ & $0.005^{\mathrm{c}}$ & $0.9 \pm 0.6$ & $0.010^{\mathrm{d}}$ \\
\hline
\end{tabular}

${ }^{c} \mathrm{p}<0.05$ vs. control group; ${ }^{\mathrm{d}} \mathrm{p}<0.05$ vs. NaF group; $\mathrm{n}=10$ 

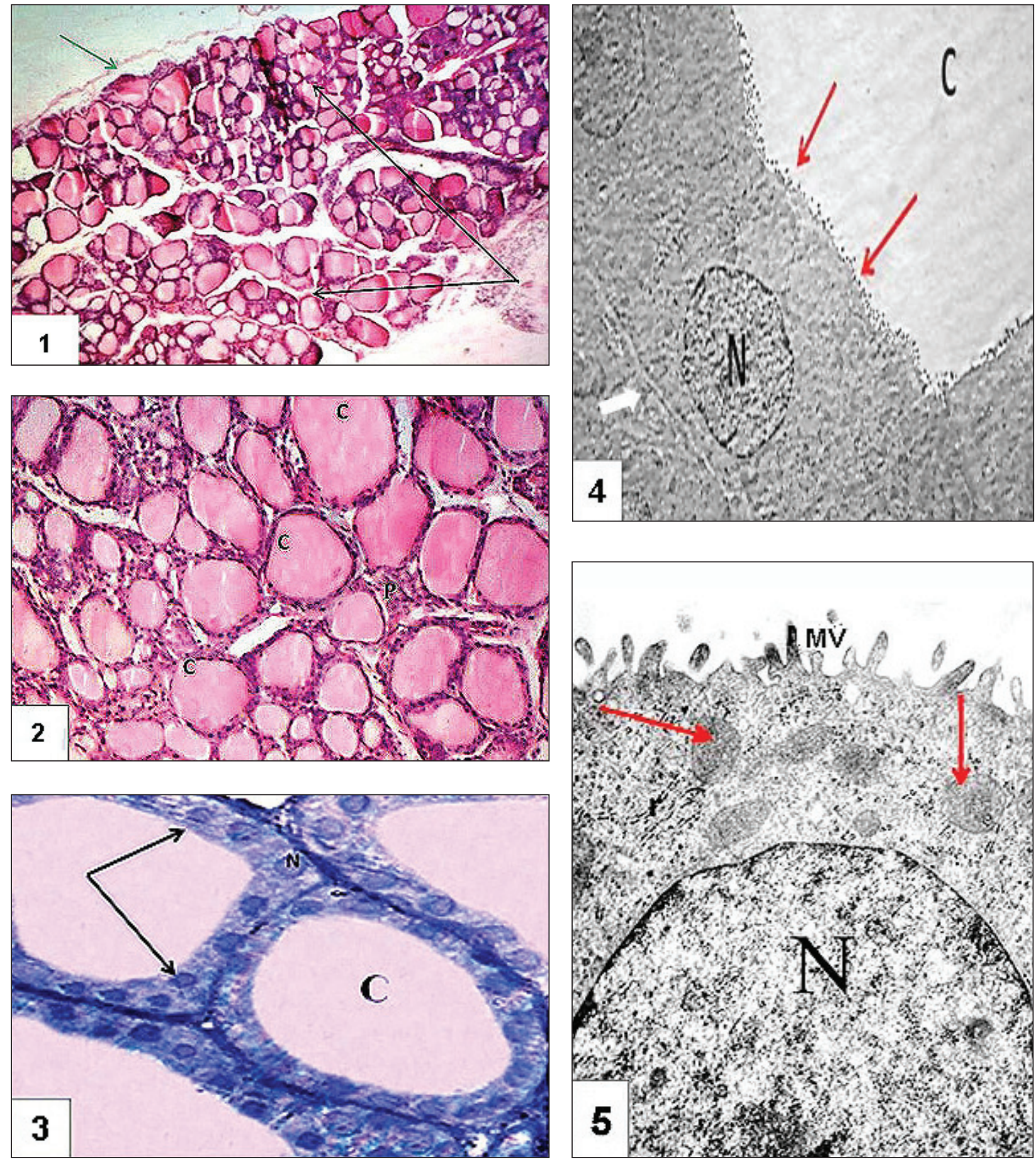

Photomicrographs of thyroid tissue from rats of control group showing:

Figure 1. Normal lobular (black arrows) architecture; variable sized follicles, large follicles at periphery of lobules. Notice the connective tissue capsule (green arrow). $\mathrm{H} \& \mathrm{E} \times 40$.

Figure 2. Different-sized follicles separated by interfollicular cells (P). Lumina filled with colloid (C). H\&E $\times 100$.

Figure 3. Thyroid follicles lined by a single layer of cuboidal epithelium (arrows), with central rounded nuclei (N) and lumina field with colloid(c). Toluidine blue $\times 1000$.

Figure 4. Thyroid follicle lined by single layer of cuboidal cells, and a lumen filled with colloid (C). Notice the large rounded euchromatic nuclei (N), numerous short microvilli (red arrows), and the basement membrane (short arrow). TEM $\times 2900$.

Figure 5. A follicular cell with paralleled cisternae of rough endoplasmic reticulum (r), large rounded euchromatic nucleus $(\mathrm{N})$, numerous mitochondria (arrows) and short apical microvilli (MV). TEM ×14000. 

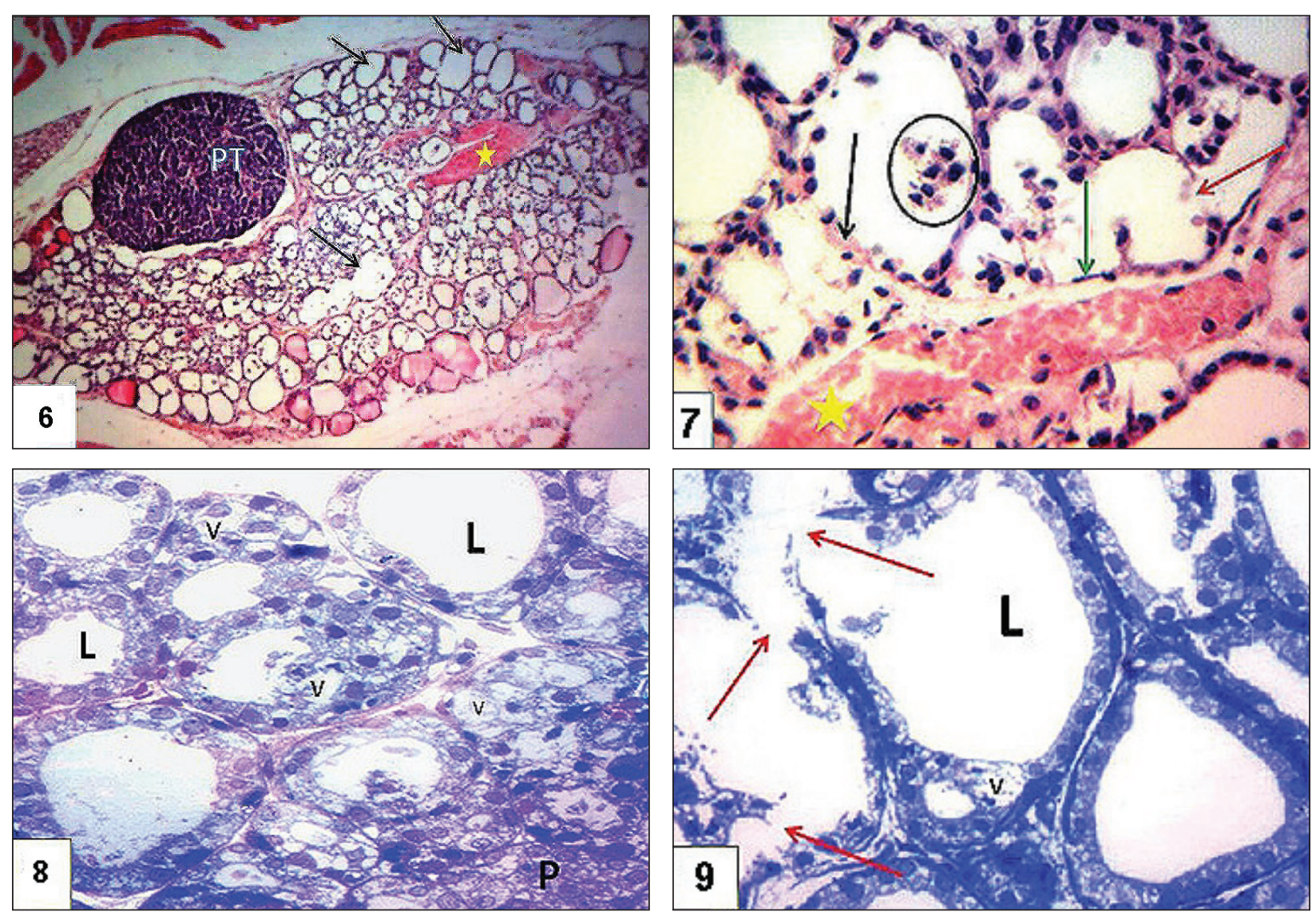

Photomicrographs of thyroid tissue from rats of $\mathrm{NaF}$ group showing:

Figure 6. Loss of lobular architecture, numerous small sized follicles, some follicles were ballooned with absence of colloid (arrows), and vascular congestion (star). Pt; parathyroid gland. $\mathrm{H} \& \mathrm{E} \times 40$.

Figure 7. The epithelial lining of follicles; some cells with deep acidophilic cytoplasm and small condensed nucleus (black arrow), others were flattened (green arrow), areas of degenerations of the basement membrane (red arrow). Notice the desquamated cells in the lumen (circle) and vascular congestion (star). $\mathrm{H} \& \mathrm{E} \times 400$.

Figure 8. Follicular cells with vaculated cytoplasm $(\mathrm{V})$ and absence of colloid $(\mathrm{L})$. Toluidine blue, $\times 400$.

Figure 9. Distended follicles with absence of colloid (L), disrupted basement membrane with fusion of the lumina (red arrows). Toluidine blue $\times 1000$.

apical lysosomal granules (Figure 13). Some follicles appeared with denuded areas of basement membrane after desquamation of cells. Their lumina appeared devoided of colloid and filled with remnants of the desquamated cells (Figure 14).

$\mathrm{NaF}+\mathrm{Curcumin}$ group. The curcumin treated group showed restoration of the normal histological structure. Normal lobular architecture was restored, follicles of variable sizes were observed, lumina of most follicles were filled with colloid (Figure 15). The follicular wall was intact and follicles were lined with a single layer of cuboid cells with some flat squamous cells. Inter-follicular cells were present between the follicles (Figures 16, 17). Most follicles were lined with cuboid cells containing large rounded euchromatic nuclei and apparently normal numerous mitochondria with intact cristae, numerous apical microvilli, and lysosomes with myelin figures. The basement membrane appeared more or less like normal (Figure 18).

\section{Discussion}

Laboratory results of this study showed that exposure to fluoride in the $\mathrm{NaF}$ group caused a significant reduction in serum levels of T3 and T4 with a significant compensatory increase in TSH compared to the control group. While administration of curcumin showed significant reduction of TSH level compared to $\mathrm{NaF}$ group toward the normal levels. The NaF af- 

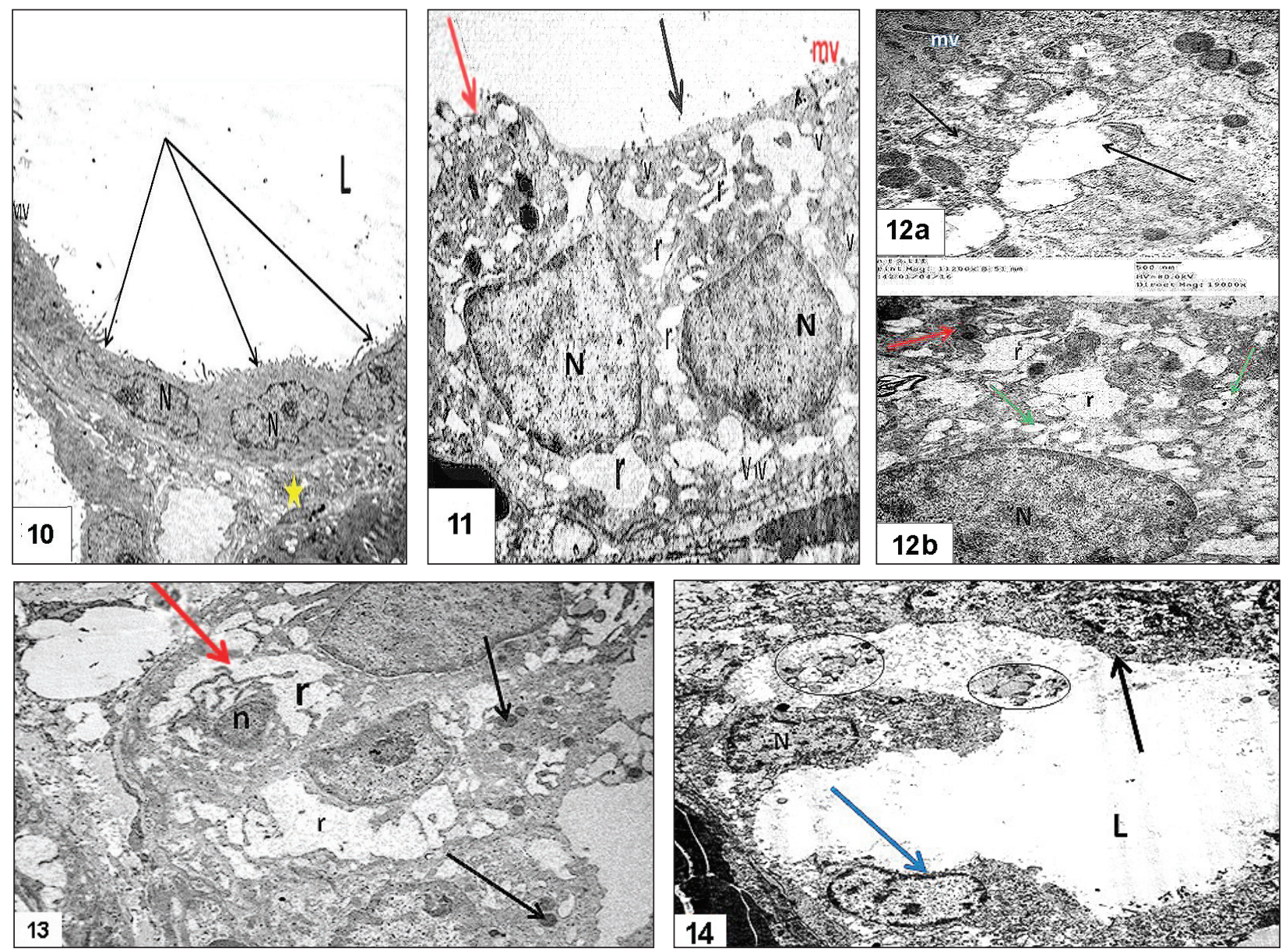

Electron photomicrographs of $\mathrm{NaF}$ group showing:

Figure 10. A follicle lined with flat cells (arrows). Notice irregular nuclei (N), sparse microvilli (MV), absence of colloid (L) and the congested blood capillary (star). TEM $\times 2900$.

Figure 11. A follicular cell (red arrow) with irregular heterochromatic nucleus $(\mathrm{N})$. The other cell (black arrow) showing dilatation of almost cisternae of rough endoplasmic reticulum $(r)$ with numerous vacuoles $(\mathrm{V})$. Notice infrequent microvilli $(\mathrm{mv})$. TEM $\times 5800$. Figure 12. a) Swollen mitochondria with disrupted cristae (arrows). TEM X19000; b) Numerous cytoplasmic vacuoles (green arrow), dilated rER (r), and apical lysosome (red arrow). TEM $\times 10000$.

Figure 13. Thyroid follicle lined with stratified cells, the basal cell (red arrow) shows dense small nucleus (n), the superior cell shows numerous apical dens lysosomal granuels (black arrow). Notice dilated rER (r), thickened basement membrane (white arrow). TEM $\times 4800$.

Figure 14. An electron micrograph of $\mathrm{NaF}$ group showing abnormal thyroid follicle lined by degenerated cells (blue arrow) with remnants of desquamated cells in the lumen (circles) leaving denuded areas of basement membrane (black arrow). Notice the absence of colloid (L). TEM $\times 2900$.

fected the thyroid homeostasis by competitively inhibiting iodide uptake at the sodium iodide symporter of the thyroid gland, which resulted in a decreased synthesis of the thyroglobulin and reduced circulating thyroid hormone levels (Rillema et al. 2000; Bouaziz et al. 2004; Khan et al. 2005; Nabavi et al. 2011).

In the current work, alterations in the thyroid gland function in the NaF group were confirmed by the histological finding of the thyroid tissue. The sections showed different morphological features: disor- ganized follicles of different diameters where some follicles became largely distended and ballooned. The increase in size of follicles when trophic signals or functional demand increased was considered as an adaptive change to fulfill needs (Durrant-Peatfield 2005). Most of the follicles were small in size. Beside the degeneration signs observed in this study they were in line with the results of Mohamed et al. (2016) and Liu et al. (2002). The decreased height of cells (from cuboid to squamous) reflected the decreased activity of the follicular cells (Junqueira and Carneiro 

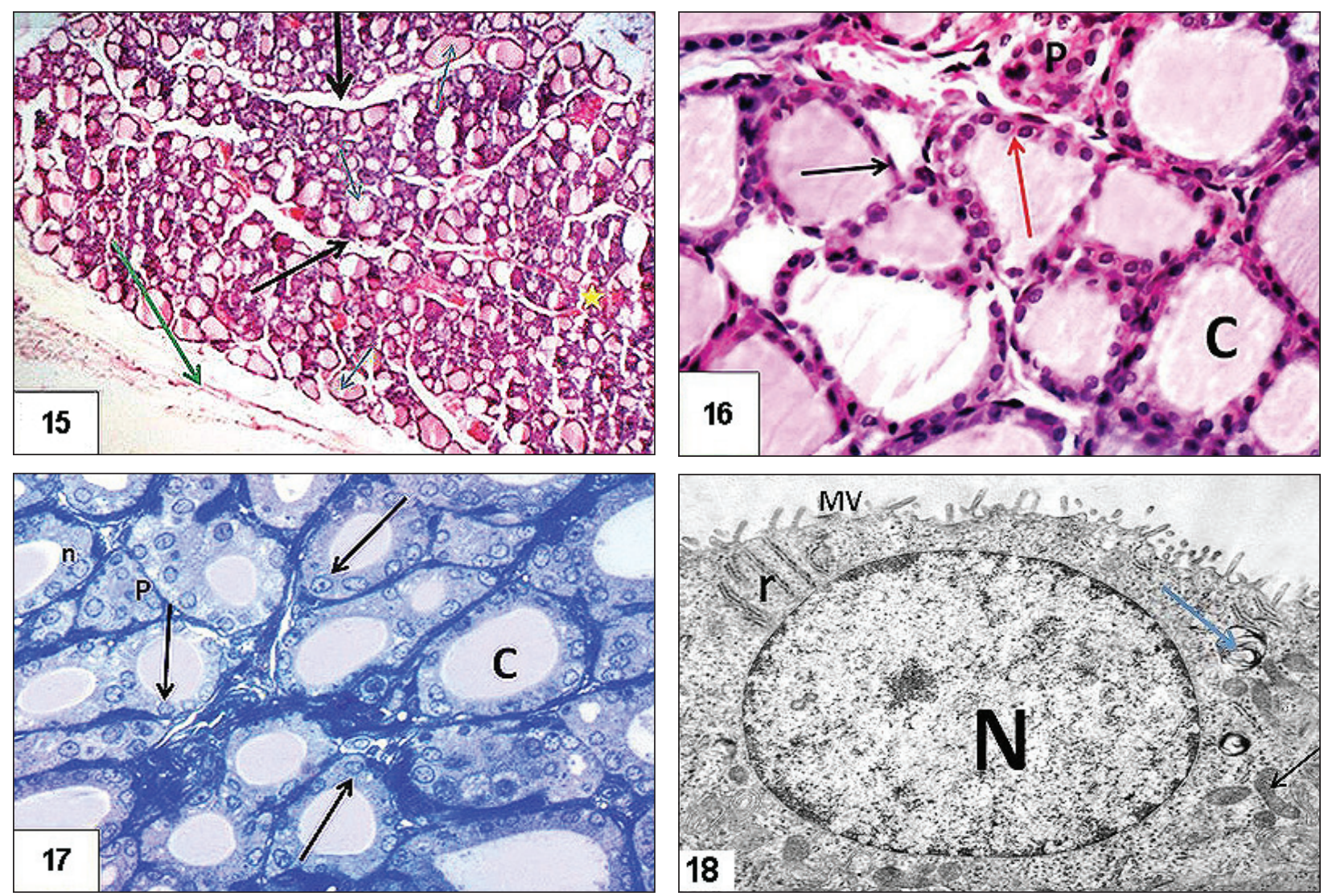

Photomicrographs of thyroid tissue from rats of $\mathrm{NaF}+\mathrm{Curcumin}$ group showing:

Figure 15. Return of normal lobular (black arrows) architecture; variable sized follicles, the large follicles at periphery of lobules (red arrow). Notice the connective tissue capsule (green arrow). H\&E $\times 40$.

Figure 16. Thyroid follicles lined mostly by a single layer of cubical cells (red arrow) and some flat squamous cells (black arrow). Notice colloid (C) and intact follicular wall. P; interfollicular cells. H\&E $\times 1000$.

Figure 17. Different-sized follicles, most lumina of follicles are filled with colloid (C). Follicles are lined by a single layer of cuboidal cells (arrows) with vesicular nuclei (n). Notice the interfollicular cells (p). Toluidine blue $\times 400$.

Figure 18. Cuboidal cell from the lining of follicle with large rounded euchromatic nucleus $(\mathrm{N})$, numerous mitochondria (black arrow), intact rER (r), numerous apical microvilli (MV) and the normal basement membrane (arrow heads). Notice lysosomes with myelin figure (blue arrow). TEM $\times 7200$.

2003). NaF-induced apoptosis by oxidative stress lead to a lipid peroxidation and the release of the cytochrome $\mathrm{C}$ into the cytosol and further triggering of caspase cascades, leading to an apoptotic cell death (Thrane et al. 2001). The presence of the vacuolations in the cytoplasm suggested TSH stimulation of the follicular cells. Several studies (Bouaziz et al. 2005; Rajkovic et al. 2006) have found that the early response of TSH stimulated thyroid follicular cells is engulfment of the colloid material from the follicular lumen into the apical cytoplasm of thyrocyte in the form of membrane bound colloid droplets, which could explain the presence of cytoplasmic vacuolations with decreased luminal colloid, which is also in agreement with the data of Bouaziz et al. (2005). The degenerative changes of the follicular epithelial cells could be explained by Barbier et al. (2010) who have suggested that fluoride interacts with a wide range of cellular processes, such as gene expression, cell cycle, proliferation and migration, respiration, metabolism, ion transport, secretion, apoptosis, and oxidative stress. Congestion of capillaries could be attributed to the high level of TSH. The epithelial stratification of the follicular lining, observed in this work, could be a compensatory mechanism and might be attributed to an increased TSH level. TSH is responsible for the proliferative activity of follicular cells and release of growth factor that modulate folliculogenisis (Trabelsi et al. 2001). Fluoride itself is mutagenic as it causes uncontrolled proliferation of cells (Pereira et al. 2011). 
In the present study, at the ultrastructural level observed degenerated mitochondria could be explained by Shivarajashankara et al. (2001) who have found that lipid peroxidation induced by $\mathrm{NaF}$ impairs a variety of intra and extra mitochondrial membrane systems that may contribute to apoptosis. Fluoride induced major pathological changes in nuclei. Glandular over stimulation because of the breakdown of DNA and chromatins terminal kinase was involved in NaF-induced apoptosis (Rubin and Strayer 2008). The observed dilation of the rough endoplasmic reticulum might be due to synthesis of secretory products greater than their removal by transport mechanisms. This has been according to Anuradha et al. (2001).

Administration of curcumin in the $\mathrm{NaF}+\mathrm{Cur}$ group markedly improved these morphological changes. Curcumin produced a significant improvement in the thyroid histology, the follicular lumina contained colloid, and the follicular cells appeared healthy. Curcumin can modulate the production of various inflammatory mediators, inflammatory cytokines such as interleukin-6, and inflammatory enzymes such as cyclooxygenase-2, thereby showing a potent anti-inflammatory activity (Chen et al. 2008). In this study, the diminished hyperplasia in the thyroid gland of rats after curcumin administration also suggested an antiproliferative activity of curcumin.
Similar inhibitory effect on the proliferation of thyreocytes has been described in a study dealing with the propyl-thiouracil-induced hypothyroidism in rats treated with vitamin E (Oner et al. 2003). Curcumin exerts anti proliferative action via protein kinase C (Korutla and Kumar 1994). The increased myelin figures and lysosomal content of the follicular cells in $\mathrm{NaF}+\mathrm{Cur}$ group could simply be a reflection of enhanced cellular secretory activity induced by high levels of circulating TSH in response to diminished synthesis of T3and T4 (Miquelis and Simon 1981). These ultrastructural findings were similar to the finding reported by other researchers (Bouaziz et al. 2005, Zhan et al. 2006).

\section{Conclusions}

Sodium fluoride affected both the function and structure of the thyroid gland while curcumin protects against these toxic effects.

It was recommended to re-examine the safety profile of the sodium fluoride ratio used in fluorination of water. More studies are also needed to fully evaluate the efficacy and the safety of reformulated curcumin, the structural analogues of curcumin, as well as the combination of curcumin with existing therapies that might hold great promise in the future.

\section{References}

Anuradha CD, Kanno S, Hirano S. Oxidative damage to mitochondria is a preliminary step to caspase-3 activation in fluoride-induced apoptosis in HL-60 cells. Free Radic Biol Med 31, 367-373, 2001.

Bancroft JD, Gamble M. Theory and Practice of Histological Techniques (6th ed.). Churchill Livingstone, Elsevier, 2008.

Barbier O, Arreola-Mendoza L, Del Razo LM. Molecular mechanisms of fluoride toxicity. Chem Biol Interact 188, 319-333, 2010.

Bishayee K, Khuda-Bukhsh AR. 5-lipoxygenase antagonist therapy: a new approach towards targeted cancer chemotherapy. Acta Biochim Biophys Sin (Shanghai) 45, 709-719, 2013.

Bouaziz H, Ammar E, Ghorbel H, Ketata S, Jamoussi K, Ayadi F, Guermazi F, Zeghal N. Effect of fluoride ingested by lactating mice on the thyroid function and bone maturation of their suckling pups. Fluoride 37, 133-142, 2004.

Bouaziz H, Soussia L, Guermazi F, Zeghal N. Fluoride-induced thyroid proliferative changes and their reversal in female mice and their pups. Fluoride 38, 185-192, 2005.

Carton RJ. Review of the 2006 United States National Research Council Report: Fluoride in drinking water. Fluoride 39, 163-172, 2006.

Chen D, Nie M, Fan MW, Bian Z. Anti-inflammatory activity of curcumin in macrophages stimulated by lipopolysaccharides from Porphyromonas gingivalis. Pharmacology 82, 264-269, 2008.

De Felice M, Postiglione MP, Di Lauro R. Minireview: thyrotropin receptor signaling in development and differentiation of the thyroid gland: insights from mouse models and human diseases. Endocrinology 145, 4062-4067, 2004.

Durrant-Peatfield B. The effects of fluoride on the thyroid gland. Synthesis/Regeneration, Election 2004: Green analyses, Biodevastation, Winter 2005. 
El-Marakby DM, Ismail DI. Histological and immunohistochemical study on the adverse effects of sodium chlorate on the pituitary-thyroid axis of albino rats and the possible protective effect of curcumin. Egypt J Histol 36, 681-690, 2013.

Gartner LP, Hiatt JL. Color Textbook of Histology (3rd ed.). Saunders, Elsevier, 2007.

Graham L, Orenstein JM. Processing tissue and cells for transmission electron microscopy in diagnostic pathology and research. Nat Protoc 2, 2439-2450, 2007.

Irizarry L, Youssef NA, Wray AA. Thyroid Hormone Toxicity (Ed. Tarabar A). Medscape, 2014. https://emedicine. medscape.com/article/819692-overview\#showall

Jayaprakasha GK, Rao LJ, Sakariah KK. Antioxidant activities of curcumin, demethoxycurcumin and bisdemethoxycurcumin. Food Chemistry 98, 720-724, 2006.

Junqueira LC, Carneiro J. Basic Histology: Text\&Atlas (10th ed.). McGraw-Hill Co., New York, 2003.

Khan MA, Fenton SE, Swank AE, Hester SD, Williams A, Wolf DC. A mixture of ammonium perchlorate and sodium chlorate enhances alterations of the pituitary-thyroid axis caused by the individual chemicals in adult male F344 rats. Toxicol Pathol 33, 776-783, 2005.

Kita T, Imai S, Sawada H, Kumagai H, Seto H. The biosynthetic pathway of curcuminoid in turmeric (Curcuma longa) as revealed by 13C-labeled precursors. Biosci Biotechnol Biochem 72, 1789-1798, 2008.

Korutla L, Kumar R. Inhibitory effect of curcumin on epidermal growth factor receptor kinase activity in A431 cells. Biochim Biophys Acta 1224, 597-600, 1994.

Liu GY, Chai CY, Kang SL. Effects of fluoride on the ultrastructure of thyroid in chicks. Chin J Vet Sci 22, 512-514, 2002.

Manolova Y, Deneva V, Antonov L, Drakalska E, Momekova D, Lambov N. The effect of the water on the curcumin tautomerism: A quantitative approach. Spectrochim Acta A Mol Biomol Spectrosc 132, 815-820, 2014.

Miquelis R, Simon C. The thyroid lysosomal system: dynamic state of the organelles in relation to iodine release. Eur J Cell Biol 24, 70-73, 1981.

Mohamed HZ, Ragab IK, Ghaffer HH. A histological study on the possible protective effect of selenium against chromium-induced thyrotoxicity in adult male albino rats. The Egyptian Journal of Histology 39, 1-11, 2016.

Nabavi SF, Moghaddam AH, Nabavi SM, Eslami S. Protective effect of curcumin and quercetin on thyroid function in sodium fluoride intoxicated rats. Fluoride 44, 147-152, 2011.

Ng JC, Wang J, Shraim A. A global health problem caused by arsenic from natural sources. Chemosphere 52, 13531359, 2003.

Oner J, Kukner A, Oner H, Ozan E, Yekeler H. Effect of vitamin E on follicular cell proliferation and expression of apoptosis-associated factors in rats with 6-N-propyl-2-thiouracil-induced goitrogenesis. Folia Histochem Cytobiol 41, 213-217, 2003.

Patil VV. Dhurvey VT. Exposure to sodium fluoride affects thyroid follicular cells in albino rats. Int J Plant Animal Environ Sci 5, 56-61, 2015.

Pereira M, Dombrowski PA, Losso EM, Chioca LR, Da Cunha C, Andreatini R. Memory impairment induced by sodium fluoride is associated with changes in brain monoamine levels. Neurotox Res 19, 55-62, 2011.

Petersen PE, Lennon MA. Effective use of fluorides for the prevention of dental caries in the 21st century: the WHO approach. Community Dent Oral Epidemiol 32, 319-321, 2004.

Rajkovic V, Matavulj M, Johansson O. Light and electron microscopic study of the thyroid gland in rats exposed to power-frequency electromagnetic fields. J Exp Biol 209, 3322-3328, 2006.

Rillema JA, Yu TX, Jhiang SM. Effect of prolactin on sodium iodide symporter expression in mouse mammary gland explants. Am J Physiol Endocrinol Metab 279, E769-E772, 2000.

Rubin R, Strayer DS. The Endocrine System. In: Rubin's Pathology: Clinicopathologic Foundation of Medicine (5th ed.), (Ed. Rubin E), pp. 935-973, Lippincott Williams \& Wilkins, 2008.

Shepherd G. Fluoride. In: Encyclopedia of Toxicology Vol. 2 (2nd ed.), pp. 342-343, Elsevier, Academic Press, 2005.

Shivarajashankara YM, Shivashankara AR, Rao SH, Bhat PG. Oxidative stress in children with endemic skeletal fluorosis. Fluoride 34, 103-107, 2001.

Surh YJ, Chun KS, Cha HH, Han SS, Keum YS, Park KK, Lee SS. Molecular mechanisms underlying chemopreventive activities of anti-inflammatory phytochemicals: down-regulation of COX-2 and iNOS through suppression of NF-kappa B activation. Mutat Res 480-481, 243-268, 2001.

Thrane EV, Refsnes M, Thoresen GH, Lag M, Schwarze PE. Fluoride-induced apoptosis in epithelial lung cells involves activation of MAP kinases 338 and possibly JNK. Toxicol Sci 61, 83-91, 2001.

Tietz NW. Tietz Textbook of Clinical Chemistry (2nd ed.), (Eds. Burtis CA, Ashwood ER). WB Saunders, 1994. 
Trabelsi M, Guermazi F, Zeghal N. Effect of fluoride on thyroid function and cerebellar development in mice. Fluoride 34, 165-173, 2001.

Whithead TP, Thorpe GH, Carter TJ, Kricka LJ. Enhanced luminescence procedure for sensitive determination of peroxidase-labelled conjugates in immunoassay. Nature; 305, 158-159, 1983.

Zhan X, Xu Z, Li J, Wang M. Effects of excessive feed fluorine on structure and function of thyroid gland in piglets. J Chinese Cereals and Oils Assoc 1, 117-121, 2006. 